\title{
E-Learning Using Open Source Software in African Universities
}

\author{
Nicholas Mavengere ${ }^{1}$, Mikko Ruohonen ${ }^{1}$, and Paul Nleya ${ }^{2}$ \\ ${ }^{1}$ School of Information Sciences, University of Tampere, Finland \\ \{nicholas.mavengere, mikko.j.ruohonen\} @uta.fi \\ ${ }^{2}$ Educational Technology Department, University of Botswana, Botswana \\ nleyapt@mopipi.ub.bw
}

\begin{abstract}
The use of technology in education specifically for enhancing learning is of immense value for improving education delivery. This article serves to highlight the research project to be done by the University of Tampere, University of Botswana and Catholic University of Mozambique. The aim of the research is to investigate how low resourced higher education institutes could make use of free and open source technologies to enhance education delivery. The community of inquiry is used as background theory because it also seeks potential to break new ground pedagogically by addressing the challenge to scientifically explore the combination of pedagogical principles and new technology that will advance the evolution of higher education. The expected results include critical success factors in implementing learning management systems in developing countries and models of open source learning management use.
\end{abstract}

Keywords: learning management systems, open source software, low resourced education institutes, community of inquiry.

\section{Introduction}

The use of technology in education is of differing dimensions but however its value is equally important. For instance, in education technology can be used for storing students' records, that is university information system, and also technology can be used for learning purposes, that is, learning management systems. It is important to study the technology used for learning for several reasons, for example, it is of direct benefit to the main education stakeholders, students and also Marshall and Ruohonen [1] noted that the use of technology in classroom is still a challenge both in developed and developing countries. Therefore, it is of value to improve how to effectively and efficiently make use of technology in classroom.

Free and open source software (FOSS) is widely considered to be a tool for promoting ICT in developing countries owing mainly to advantages like reduced cost of ownership, avoidance of vendor lock-in and development of indigenous technologies [2, 3]. In other words, FOSS is a considered to be important for removing the so-called 'digital divide' between developed countries and the rest of 
the world. Thus, a recent trend shows that governments of developing countries, especially from Africa, are adopting FOSS over proprietary ICT. Therefore, this research seeks to utilize FOSS because of the mentioned advantages. The FOSS systems that will be used in this research are learning management systems (LMS).

This research seeks to investigate how low resourced higher education institutes could make use of free and open source technologies to enhance education delivery. The practical problem which this project seeks to solve is to reduce the impact of inadequate resources in higher education institute in developing countries. This is a common problem at most institutes in Africa. The aim of this project is to make use of free and open source technologies to reduce this problem. Technology offers a big opportunity for African education institutes to reduce the impact of lack of resources. The significance of the project is to offer sustainable solution to lack of resources at African education institutes. The research question to be addressed in this research is; how to make use of eLearning in African education institutes in order to foster the use of technology in higher education context?

\section{Research Background}

\subsection{Practical Background}

Mavengere and Ruohonen [4] note five key issues in application of LMS in African universities as computer literacy, computer infrastructure, collaboration/sharing culture, human resource (IT staff) and leadership support. These are essential aspects which have to be addressed before starting a technology related project in Africa. We will briefly discuss these issues before explaining the proposed Case Studies in this research.

The main challenge for IT-enhanced education in developing countries is availability of computer infrastructure [5]. Therefore, firstly the need for computer infrastructure has to be addressed before initiating any technology related project in Africa. In this research we access the computer infrastructure availability at University of Botswana and Catholic University of Mozambique and make adequate preparations. The second step is to guarantee computer literacy, as it was noted as also an essential aspect for LMS in African universities [4]. Third aspect and related to computer literacy is availability of the required human resource expertise, such as, IT technicians and managers. This research project will incorporate student and staff exchange programmes from African universities to University of Tampere as a well to improve the human resources on IT use in education. Moreover, joint intensive courses will be done by all partner universities to share experience and learn from each other. Last, two other important aspects for application of LMS in African universities are based on organizational behaviour namely collaboration culture and leadership support. Collaboration is important especially in African education context where resources are limited in that there is mutual benefit by the sharing parties. On the other hand, leadership support is the backbone in any change initiative and use of technology is education requires support from the policy makers and administrators. 


\subsection{Theoretical Background}

The community of inquiry framework, Figure 1, fits as the theoretical basis of this research as it also seeks potential to break new ground pedagogically by addressing the challenge to scientifically explore the combination of pedagogical principles and new technology that will advance the evolution of higher education [6]. Community of inquiry is meaningful association in addressing a problem, for instance, in the project the partners University of Botswana, Catholic University of Mozambique and University of Tampere make up the community that is multi-disciplinary and includes discourse. The philosophical basis of this research just as elaborated by the framework is collaborative constructivism. The core elements of a collaborative constructivist learning environment identified in the framework and that are required for a purposeful learning are teaching, cognitive and social presence. The first element, social presence is the participants' ability to recognize themselves as part of the community. Thus in the project we aim to make every project member and participants to identify themselves with the project and its activities as a single family. Cognitive presence, the second element of community of inquiry framework, is the degree to which learners are able to construct and verify meaning through continuous reflection and dialogue in a community of inquiry. Lastly, teaching presence includes three main responsibilities to be catered for in this project as elaborated by Garrison, Cleveland-Innes and Fung [6] "the first of the primary teaching presence responsibilities is establishing curriculum content, learning activities, and timelines. The second responsibility is monitoring and managing purposeful collaboration and reflection. The third is ensuring that the community reaches the intended learning outcomes by diagnosing needs and providing timely information and direction" (p.32).

Blended learning has transformative potential of learning in the context of the challenges facing higher education [7]. In agreement with Garrison and Kanuka [8] in simple terms blended learning "is the thoughtful integration of classroom face-to-face learning experiences with online learning experiences" (p.96). Blended learning that is the use of eLearning using open source software and face-to-face teaching will be

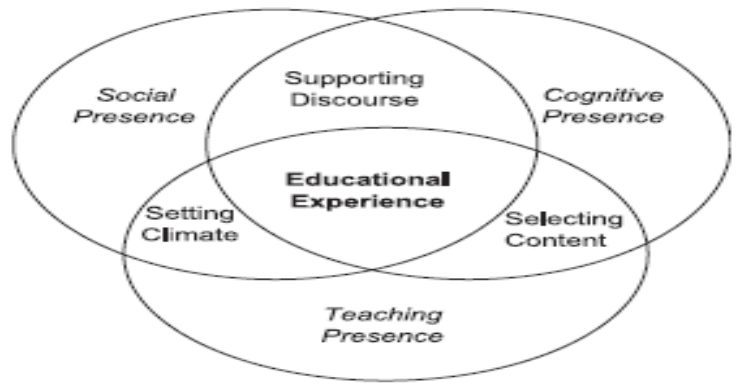

Fig. 1. Community of inquiry [9] 
utilized in this project [7]. Blended learning has many advantages as noted by Garrison and Kanuka [8], such as, "effective integration of the two main components (face-to-face and Internet technology) such that we are not just adding on to the existing dominant approach or method. What makes blended learning particularly effective is its ability to facilitate a community of inquiry" (p.97).

\section{$3 \quad$ Research Methodology}

This article is based on a proposed research to be conducted at University of Botswana and Catholic University of Mozambique. The research project includes joint courses among the partner universities, mirror courses (same courses) done at the partner universities and exchange programs for teachers and students. The value of the exchange program is in sharing academic and professional experiences and culture. The teacher exchange will enable the visiting teacher to give classes and carry out research at the host university. The students exchange will offer students a different learning environment. The intensive courses will expose the partner universities to diverse cultures in jointly offering the courses. There will also courses on the same topic simultaneously done at the partner universities in order to share experiences. All these project activities will also be support by use of a learning management system. Case studies from each partner university will also be analysed and reported. Below is a summary from each partner university.

\subsection{University of Botswana}

The University of Botswana is in need of e-learning individual and institutional capacity development. This project is the right step in ensuring this as the university seeks to explore the process of eLearning integration at the UB using both proprietary (WebCT/Blackboard) and alternative Open Educational Resources (OER) (Moodle). The UB is currently using WeBCT/Blackboard for its eLearning and concurrently piloting with Moodle given that Moodle is low cost compared to WebCT/Blackboard where the UB spends $\$ 40,000$ on license and service agreement fees and over $\$ 3$ million for upgrades annually. There is therefore ample opportunity and relevance to explore the benefits of Moodle as a new learning management tool at the UB in the Botswana study. The University of Tampere (Finland) has expertise in the implementation of Moodle and has worked in the African context (Mozambique) assisting in the execution of Moodle OER. The Botswana case study therefore explores the process of integrating ICT into the tertiary curriculum focusing on the process of eLearning integration at the UB using identified SAM and other relevant conceptual frameworks. Therefore, the teacher and students exchange to the University of Tampere will aid in that the required expertise and experienced will be gained from the exchange program. Moreover, the university will host a joint intensive course which will provide valuable experience in its e-learning ambitions. 


\subsection{Catholic University of Mozambique}

Catholic University of Mozambique (UCM) has recently started experimenting with aspects of an e-learning mode of delivery by being part of the African Virtual Open Initiatives and Resources (AVOIR) Network, including universities of seven countries in sub-Saharan Africa with the objective to establish a group of universities in Africa who collaboratively develop open source software (KEWL.NextGen) to promote the innovative applications of ICT in higher education. However, in 2009, a general consensus was reached on the use of Moodle as the preferred Learning Management System. The Department of Information Technology (FGTI) in Beira thus became the pioneer on the use of Moodle in UCM. The FLOSS-AHEAD project will be of immense value in developing required e-learning capabilities for UCM staff, students and the university as a whole. The exchange programs to Finland would of value as University of Tampere experience in Moodle use and moreover ICT in development in general. Therefore UCM intends to improve learning outcomes and student interest in IT in education and for development in general. Appreciation of the vast potential of Moodle is still being realized.

\subsection{University of Tampere}

The University of Tampere and also other universities in Finland generally use learning management systems, such as Moodle, webCT and Blackboard. However, the use of these learning management systems is very diverse with no agreed upon standards or best practices. There is room to improve the use of the learning management even though different institutes could be using different learning management system although this research advocates for FLOSS systems. Even at the same institute professors use differently technology in their classes. Thus it is motivating to draw lessons from all these different ways technology is being used and propose more efficient and effective practices that incorporate eLearning.

\section{Conclusion}

There is a need to be better employing the good technical facilities available to universities to provide equitable and quality education. Recent research, for example, $[10,11,12]$ have noted that there is a room for improvement in the application of ICTs in classrooms. Therefore, this research project is an effort to improve the use of ICTs at universities in general and with a specific focus on improving learning and interactions between main education stakeholders, students and teachers at University of Botswana and Catholic University of Mozambique. Moreover, eLearning use with support of open source software offers a plausible channel for enhancement of higher education in developing countries. One of the greatest challenges of ICT integration in education can be summarized as limited vision, policy and leadership given that ICT is changing faster than educators ability to keep track [12]. To conclude the need to conduct evidence-led research in ICT integration in higher education is noted. 


\section{References}

1. Marshall, G., Ruohonen, M.: Capacity Building for IT in Education in Developing Countries IFIP Publication. Chapman \& Hall, London (1998)

2. Lerner, J., Tirole, J.: Some Simple Economics of Open Source. Journal of Industrial Economics 50(2), 197-234 (2002)

3. Camara, G., Fonseka, S.: Information Policies and Open Source Software in Developing Countries. Journal Of The American Society For Information Science And Technology 58(1), 121-132 (2007)

4. Mavengere, N.B., Ruohonen, M.J.: Using Open Source Software for Improving Dialog in Computer Science Education - Case Mozambique University. In: Tatnall, A., Kereteletswe, O.C., Visscher, A. (eds.) ITEM 2010. IFIP AICT, vol. 348, pp. 52-61. Springer, Heidelberg (2011)

5. Kumar, R.: Proceedings of World Academy of Science, Engineering and Technology, vol. 30, pp. 1307-6884 (2008)

6. Garrison, D.R., Cleveland-Innes, M., Fung, T.S.: Exploring causal relationships among teaching, cognitive and social presence: Student perceptions of the community of inquiry framework. The Internet and Higher Education 13, 31-36 (2010)

7. El-Ghalayini, H., El-khalili, N.: An approach to designing and evaluating blended courses. Edu. Inf. Tech. 17, 417-430 (2011)

8. Garrison, R., Kanuka, H.: Blended learning: Uncovering its transformative potential in higher education. Internet and Higher Education 7, 95-105 (2004)

9. Garrison, D.R., Anderson, T.: E-Learning in the 21stCentury: A Framework for Research and Practice. Routledge/Falmer, London (2003)

10. Buettner, Y.: Teaching teachers to teach ICT integration. Education and Information Technologies 11(3), 25-26 (2006)

11. Ottevanger, W.J., van den Akker, J.H., de Feiter, L.: Developing Science, mathematics, and ICT education in sub-Saharan Africa: Patterns and promising practices. World Bank Africa Region Human Development Department, Washington, D.C (2007)

12. Ruohonen, M., Mavengere, N., Nleya, P., Deodhar, S.: The Use of Free, Libre and Open Source Software (FLOSS) for African Higher Education Advancement and Development. In: Youssef, M., Anwar, S.A. (eds.) Proceedings of the 4th Conference on e-Learning Excellence in the Middle East 2011: In Search of New Paradigms for Re-engineering Education, pp. 44-54 (2011) 